\title{
As empresas sociais de agricultura urbana e a resiliência nas cidades: movimentos populares belo-horizontinos e londrinos que desafiam a hegemonia neoliberal
}

\section{Social enterprises of urban agriculture and the resilience in cities: Belo-horizontinos and Londoners popular movements that defy the hegemony neoliberal}

\author{
Vander Luiz Aguiar [1]/vanderaguiar@pucminas.br /PUC Minas, Brasil \\ Armindo dos Santos de Sousa Teodósio [2] / PUC Minas, Brasil \\ Walter Mswaka [3] /University of Huddersfield, Inglaterra \\ Eixo Temático: Social solidarity and transformative movements \\ Agência Financiadora: Coordenação de Aperfeiçoamento de Pessoal de Nível Superior
}

\section{Resumo}

Nos dois últimos séculos a população mundial saltou de um bilhão para mais de sete bilhões de pessoas. Ademais, para o ano de 2050, estimam-se nove bilhões de indivíduos com mais de $70 \%$ deste contingente vivendo nas cidades (Santos, 1988; Durand, 1977). Cada vez mais, o mundo se torna urbano (Lefebvre, 2013) e a demanda por serviços socioambientais cresce. Neste contexto, a necessidade da população e a incapacidade dos governantes corroboram a hegemonia neoliberal, cenário em que o Estado perde poder para o setor de mercado. De formas diferentes, tanto o Brasil quanto a Inglaterra estão intensificando as suas políticas neoliberais (Maricato, 2017; Nicholls \& Teasdale, 2017), o que justifica perguntar: como as empresas sociais de agricultura urbana estão influenciando a resiliência das cidades de Belo Horizonte e de Londres. Para responder a esta pergunta, empregou-se a abordagem qualitativa como metodologia de pesquisa ao realizar um estudo de caso múltiplo holístico (Maffezzolli \& Boehs, 2016). A unidade de análise belorizontina foi o Jardim Produtivo e a londrina foi o Stamford Hill, ambas são produtoras de hortaliças. Nestas unidades, em 2016 e 2017, o autor realizou observação direta e fez entrevistas, além de recorrer a fontes documentais (Yin, 2005). A partir de parcerias entre entidades governamentais e do terceiro setor, constituiu-se o Jardim Produtivo no ano de 2007. O projeto que originou o Stamford Hill também é de 2007, mas a iniciativa veio do segundo setor. Neste último caso, uma empresa privada foi apoiada por organizações não governamentais inglesas. Os dois empreendimentos são considerados empresas sociais (Defourny \& Nyssens, 2017) de agricultura urbana (Mougeot, 2005). A gestão das duas empresas foi transferida para as comunidades locais após a constituição das mesmas. A pesquisa mostrou que, mesmo nos espaços em que predominam as empresas capitalistas, as empresas sociais podem contribuir para aumentar a resiliência (Klug, 2018) das cidades. Nos dois casos empíricos investigados, observou-se impacto ambiental favorável, uma vez que as milhas alimentares reduziram e as áreas verdes aumentaram. Ademais, a população local se sentiu mais segura com a ocupação de terrenos baldios e a oferta de produtos agroecológicos cresceu nas duas cidades, o que reduz a carga dos serviços públicos de saúde (De Oliveira Trecha et al., 2017). O trabalho mostrou também que a principal contribuição do Stamford Hill para a resiliência de Londres foi na dimensão social. As famílias de lá utilizam o espaço da horta para se confraternizarem e receberem os amigos. Neste aspecto, o Jardim Produtivo se diferenciou, uma vez que a maioria de seus trabalhadores visavam o lado financeiro do negócio. No caso brasileiro, a empresa contribuiu para que a cidade se tornasse mais resiliente na dimensão econômica, principalmente para a população de baixa renda. A principal limitação deste trabalho foi o número reduzido de casos investigados, o que inviabilizou generalizações. Por essa razão, sugere-se a abordagem de novas empresas sociais de agricultura urbana em outros trabalhos.

Palavras-chave: Empresa social, Agricultura urbana, Resiliência das Cidades, Políticas neoliberais. 


\begin{abstract}
In the last two centuries, the world population has jumped from one billion to more than seven billion people. In addition, by the year 2050 , nine billion individuals with more than $70 \%$ of this contingent living in the cities are estimated (Santos, 1988; Durand, 1977). Increasingly, the world becomes urban (Lefebvre, 2013) and the demand for socio-environmental services grows. In this context, the need of the population and the inability of the governments corroborate the neoliberal hegemony, a scenario in which the state loses power for the market sector. In different ways, both Brazil and England are intensifying their neoliberal policies (Maricato, 2017; Nicholls \& Teasdale, 2017), which justifies asking: how are social enterprises of urban agriculture influencing the resilience of the cities of Belo Horizonte and from London. To answer this question, the qualitative approach was used as a research methodology when conducting a holistic multiple case study (Maffezzolli \& Boehs, 2016). The unit of analysis belohorizontina was the Jardim Produtivo and London was Stamford Hill, both are producers of vegetables. In these units, in 2016 and 2017, the author made direct observation and did interviews, in addition to resorting to documentary sources (Yin, 2005). Starting from partnerships between governmental entities and the third sector, the Productive Garden was established in 2007. The project that originated Stamford Hill is also from 2007, but the initiative came from the second sector. In the latter case, a private company was supported by English non-governmental organizations. The two enterprises are considered social enterprises (Defourny \& Nyssens, 2017) of urban agriculture (Mougeot, 2005). The management of the two companies was transferred to the local communities after their establishment. Research has shown that, even in areas where capitalist enterprises predominate, social enterprises can contribute to increasing resilience (Klug, 2018) of cities. In the two empirical cases investigated, favorable environmental impact was observed, since the food miles reduced and the green areas increased. In addition, the local population felt safer with the occupation of vacant lots and the supply of agroecological products grew in both cities, which reduces the burden of public health services (De Oliveira Trecha et al., 2017). The work also showed that Stamford Hill's main contribution to London's resilience was in the social dimension. The families there use the garden space to get together and receive friends. In this respect, the Jardim Produtivo differed, since most of its workers were focused on the financial side of the business. In the Brazilian case, the company contributed to making the city more resilient in the economic dimension, especially for the low-income population. The main limitation of this study was the small number of cases investigated, which made generalizations unfeasible. For this reason, it is suggested to approach new social enterprises of urban agriculture in other works.
\end{abstract}

Keywords: Social enterprise, Urban agriculture, Cities resilience, Neoliberal policies. 


\section{INTRODUÇÃO}

Em meados do século passado, após a II Guerra Mundial, os países de capitalismo central mostravam as potencialidades do Estado ao realizarem grandes investimentos na qualidade de vida de seus cidadãos. Mas, nos anos de 1990, mesmo aqueles governos que exibiam políticas sociais consolidadas, já apresentavam sinais de fraqueza (Silva \& Nagem, 2016). Neste século, entre os países desenvolvidos, já se questiona a existência do estado de bem-estar social, uma vez que os governos estão transferindo as suas responsabilidades para a sociedade civil (Kerstenetzky \& Guedes, 2018). No caso da Inglaterra, por exemplo, o Estado se torna cada vez mais ausente (Nicholls \& Teasdale, 2017).

A crise que culminou na redução de investimentos governamentais em questões sociais, desencadeou-se na década de 1980 (Silva \& Nagem, 2016). Naquele período, além da baixa oferta do petróleo em níveis globais, o mundo vivia os últimos anos da Guerra Fria. Após a desagregação da União soviética, por volta de 1990, alargaram-se as fronteiras ocidentais com a expansão do modelo de capitalismo e de democracia liberal liderado pelos Estados Unidos (Munhoz, 2017). As principais características dessa crise foram a ausência do poder público, o fortalecimento do mercado e a proliferação das organizações da sociedade civil. A sua principal consequência foi o aumento da desigualdade social.

Na década de 1990, como consequência do Consenso de Washington liderado pelo Estados Unidos, os governos da América Latina também se viram obrigados a reduzirem investimentos sociais (Origuéla et al., 2019). Porém, entre os países mais pobres, como por exemplo o Brasil, os impactos negativos das políticas neoliberais são nefastos (Maricato, 2017). Nesses casos, além de aumentar a desigualdade, faltam serviços básicos: saúde, educação, moradia e segurança. Ademais, a crise financeira internacional de 2008 , originada nos Estados Unidos, atingiu todos os continentes. Embora essa crise tenha sido provocada pelo poder atribuído ao mercado (Borges et al., 2018), ela não freou a expansão neoliberal.

O desequilíbrio mundial se intensificou desencadeando o aumento da pobreza e da desigualdade em todos os continentes. Os problemas que emergiram colocaram em pauta as discussões sobre os recursos naturais e a possibilidade deles se esgotarem. No bojo dessa problematização surgiram as empresas sociais (Defourny \& Nyssens, 2017), a agricultura urbana (Mougeot, 2006), a agroecologia (Ehlers, 2017) e outros temas que estivessem relacionados com o consumismo exacerbado produzido pelo capital.

A hipótese de que o modelo de crescimento neoliberal está avançando em todos as direções já foi confirmada em outros estudos (Kerstenetzky \& Guedes, 2018). Esse fato 
implica na redução do tamanho do Estado e no aumento das demandas sociais. A partir dessas constatações, define-se como objetivo deste texto verificar como as empresas sociais de agricultura urbana estão influenciando a resiliência das cidades de Belo Horizonte e de Londres. Para alcançar esse objetivo, faz-se necessário compreender melhor os ternos "Empresas Sociais de agricultura urbana", e "Neoliberalismo".

Este trabalho se justifica pela demanda reprimida que existe entre os cidadãos das camadas mais pobres do Brasil. Diante da ausência de políticas públicas adequadas, está ficando cada vez mais difícil para as classes baixas do país acessarem os serviços sociais básicos. Adicionalmente, os brasileiros estão ingerindo doses cada vez maiores de agrotóxicos (Bombardi, 2017). O veneno, além de contaminar as plantas, espalha-se pelo ar, pela água e pela terra, o que compromete os ecossistemas. Ao abordar o tema "Empresas sociais de agricultura urbana", principalmente por investiga-lo no Brasil e na Inglaterra, espera-se identificar possíveis soluções para o caso brasileiro. Neste campo, as necessidades básicas inglesas e a contaminação por agrotóxicos ainda estão sob controle.

\section{EMPRESAS SOCIAIS}

O crescimento populacional e as consequências das crises provocadas pelo sistema capitalista explicam o aumento da demanda por serviços sociais e à baixa capacidade de respostas do Estado, o que se torna cada vez mais recorrente ao redor do mundo. Esse cenário, acrescido da insuficiência regenerativa do ecossistema, exige ações imediatas. Por isso, o tema "empresas sociais" se torna pauta relevante na agenda de discussões do século XXI. A construção de um modelo empresarial teórico, possível alternativa para a solução de parte dos problemas contemporâneos, está mobilizando pesquisadores de todos os continentes (Singer et al., 2014; Abramovay, 2016; Furtado, Teodósio, \& Guerra, 2017).

O objetivo principal de uma empresa social é preencher as lacunas criadas pela ausência governamental. Essas empresas representam um instrumento importante no campo das políticas públicas, pois elas funcionam como uma proposta alternativa ao modelo econômico que opera atualmente na maioria dos países. O termo "empresa social" ainda não está completamente definido, razões pelas quais é confundido com outros, tais como "inovação social", "empreendedorismo social", "negócio social”, etc (Agostini, 2016). Mas, formou-se um grupo multidisciplinar com mais de 200 pesquisadores, provenientes de mais de 50 países, com o propósito de definir as "empresas socias". 
Esse novo campo de estudos está se constituindo, dede o ano de 2013, ancorado pelo projeto "The International Comparative Social Enterprise Models (ICSEM)" (Gaiger et al., 2015). A estratégia do ICSEM para chegar a uma definição abrangente e consensual para o termo "empresa social" (ES) é, primeiramente, construir definições parciais a partir dos casos empíricos mais robustos dos diferentes países e, por fim, proceder a generalização do modelo (Defourny \& Nyssens, 2017). Embora existam correntes de pesquisas diferentes e mais de uma abordagem relativa às empresas sociais, neste estudo planeja-se trabalhar com a definição parcial proposta no âmbito do ICSEM.

Pelos princípios da economia clássica, a sociedade está dividida em setores conforme os objetivos de seus agentes sociais que podem ter natureza jurídica pública ou natureza jurídica privada. As organizações e propriedades pertencentes ao Estado compõem o primeiro setor e os seus agentes realizam ações com fins públicos. As empresas e as propriedades não pertencentes ao Estado compõem o segundo setor. Este setor corresponde ao Mercado e os seus agentes atuam com fins privados. Nos anos 70, ainda embasado pela economia clássica, criou-se o termo "Terceiro Setor" para justificar as ações dos agentes privados com fins públicos (Tenório, 1999).

Os dois primeiros setores da economia clássica já estão definidos e consolidados, mas as fronteiras do terceiro setor ainda estão em fase de demarcação (Salamon \& Anheier, 1992; Salamon \& Sokolowski, 2016). O terceiro setor abriga a economia social que, por natureza, deveria contrapor ao capitalismo. Mas, segundo Laville (2014) já não há mais contraposição, por essa razão, o próprio Jean-Louis Laville, em parceria com Bernard Eme, propôs a teoria da economia solidária em 1994 como alternativa às práticas capitalistas. Essa abordagem é mais enfatizada na Europa e na América Latina (Silva \& Nagem, 2016).

As empresas sociais estão sendo definidas na interseção dos três setores da economia clássica. Assim sendo, essas empresas possuem interesse geral, mas também defendem os interesses dos próprios membros. Elas usam recursos públicos, mas também se capitalizam via operações de mercado. No conjunto das empresas sociais, existem aquelas geradas pelo setor público, pelo setor de mercado e pelo terceiro setor. As suas principais características são: ações sociais, elevado grau de autonomia, participação da sociedade civil, contraposição ao mercado e reversão de seus resultados para a própria comunidade (Laville \& Nyssens, 2001; Jegers, 2008; Defourny \& Nyssens, 2017).

Considerando o universo de instituições, independentemente do setor em que estão alocadas, identificaram-se quatro modelos de empresas sociais. Aquelas sem fins lucrativos, às cooperativas ou empreendimentos de economia solidária (EES), empresas do segundo 
setor que realizam atividades sociais e as empresas que atuam no campo governamental. (Defourny \& Nyssens, 2017). Todos esses empreendimentos possuem características que os diferem das empresas que atuam exclusivamente em determinado setor, pois eles estão na interseção dos setores.

As matrizes que pelas quais as empresas sociais se constituem pertencem ao Estado, ao mercado ou ao terceiro setor. Em função da origem, esta classe de empresas apresenta características diferentes. Então, faz-se necessário saber em que proporção elas disponibilizam os seus serviços para a comunidade, como elas se posicionam entre as dimensões social, ambiental e econômica e o quão dependente elas são do mercado ou do Estado. Por todas essas questões, a tipologia de uma empresa social depende do país em que ela estiver inserida (de Andrade Silva \& Gonçalves-Dias, 2015). Assim sendo, conforme o objetivo deste texto, propõe-se analisar as empresas sociais no Brasil e na Inglaterra.

\subsection{Empresa social no Brasil}

No Brasil, não se emprega com regularidade o termo "empresa social" (Jahchan et al., 2016), mas independentemente do rótulo que se utiliza para esse tipo de organização no país, o seu objetivo é minimizar a pobreza (Furtado et al., 2017). Os pesquisadores brasileiros que participam do projeto ICSEM acreditam que os empreendimentos de economia solidária (EES) sejam os que melhor se adequem aos princípios de uma empresa social (Gaiger et al., 2015). É sabido, porém, que existem empresas com projetos sociais em outros setores, mas elas ainda não foram estudadas o suficiente para receberem a classificação de ES. No Brasil, geralmente, estudam-se os projetos e não as empresas.

Os EES são associações de pessoas e não de capital, por isso não visam tecnicamente o lucro. Ademais, elas oferecem aos seus integrantes a possibilidade de superar as limitações do trabalho individual (Silva, 2017). Os princípios que regem os EES são similares àqueles que regem às cooperativas e as suas características estão regulamentadas na Secretaria Nacional de Economia Solidária (SENAES), no âmbito do Ministério do Trabalho e Emprego (MTE). Quanto ao campo de atuação, elas podem desenvolver atividades econômicas de produção, distribuição, consumo, poupança e crédito. Os EES se caracterizam pela cooperação, autogestão, dimensão econômica e solidariedade (Palma et al., 2017).

Embora os EES atuem em seguimentos diferentes, tanto na cidade quanto no campo, eles privilegiam as atividades agrícolas de produção e transformação (Gaiger et al., 2015). O processo de comercialização dos agricultores, no âmbito dos EES, sugere o princípio da 
reciprocidade na perspectiva de Karl Polanyi e possibilita o controle de cadeias curtas (Sabourin, 2017; Darolt, 2012). A troca de serviços ou produtos entre agricultores e o contado deles direto com os consumidores reduz o custo de transação. A relação de reciprocidade nos EES vai além da dimensão material em uma troca, o que garante prosperidade aos grupos.

Ademais, existem políticas públicas que facilitam a produção e comercialização agrícola, embora o governo invista pouco e o acesso aos programas seja restrito (Sabourin, 2017). Entre os recursos para financiar a produção, destaca-se o Programa Nacional de Fortalecimento da Agricultura Familiar (PRONAF), criado em 1995. Entre as políticas voltadas para a distribuição dos alimentos, destacam-se o Programa de Aquisição de Alimentos (PAA) e o Programa Nacional de Alimentação Escolar (PNAE), criado em 1955. Por meio do PAA, o próprio governo compra a produção do agricultor e o PNAE garante ao produtor a venda direta de seus produtos para as escolas públicas (Rodrigues et al., 2017).

Os EES agrícolas, principalmente nas cidades, criam postos de trabalho e facilita 0 abastecimento alimentício nas regiões metropolitanas (Rodrigues et al., 2015). Além disso, os EES promovem benefícios intangíveis, tais como: a mudança de hábito alimentar, a redução do estresse, a integração familiar e a sensação de segurança (Darolt, 2012; Eckert, 2016). Em suma, essas empresas são instrumentos para o combater a pobreza e minimizar a desigualdade no país. Por essas razões, a economia solidária foi implantada no Brasil como política pública em 1995 (de Souza Prates et al., 2016; Singer et al., 2014).

Entre os principais impeditivos de sucesso que se identificaram para esse grupo de empresas sociais, podem-se destacar o acesso ao mercado, o acesso ao crédito, a concorrência com as empresas capitalistas, a falta de assistência técnica para a produção orgânica e as descontinuidades na execução das políticas públicas (Sabourin, 2017; Silva, 2017; Singer et al., 2014). Para melhorar a probabilidade de sucesso para essas empresas, sugere-se que elas se articulem com o poder público, com as universidades e com as incubadoras de empresas sociais (Gallo, Martins, \& Peres, 2016).

\subsection{Empresa social na Inglaterra}

O termo "Empresa Social" já está definido na Inglaterra e é largamente utilizado, mas ele não coincide com a definição que se propõe construir no âmbito do projeto ICSEM. As práticas inglesas nesse campo estão contribuindo para uma definição geral do terno, elas se configuram como casos particulares de empresas sociais. Pela definição inglesa, é desejável que a empresa tenha objetivos sociais e que o seu retorno financeiro seja aplicado em projetos 
sociais. Ademais, a empresa deve ter mecanismos que impedem a maximização de lucros para os acionistas ou proprietários (Department for Trade and Industry, 2002; Mswaka, 2015). Esses princípios são necessários, mas não são suficientes, conforme o proposto pelo EMES.

Adicionalmente, o governo tem alterado a classificação das empresas sociais no país conforme lhe convém. Após a crise financeira de 2008, ele decidiu cortar os investimentos do setor público para aplicar no setor privado. Então, agraciou os seus maiores bancos com aproximadamente $£ 193$ bilhões, valor equivalente a seis vezes o que se doou para todo o setor de caridade no mesmo período e quase o dobro do volume de negócios praticados pelas cooperativas e pelo setor mutuário (Ridley-Duff \& Bull, 2015). Como está faltando recursos públicos para as empresas sociais, elas dependem de aportes privados, o que dificulta limitar a distribuição dos lucros entre os investidores.

Em função das políticas públicas praticadas atualmente na Inglaterra, as empresas sociais estão se aproximando daquelas convencionais que atuam no mercado capitalista. Conforme Besley e Ghatak (2017), isso representa riscos para a economia social inglesa, pois o mercado não combina com altruísmo e talvez seja complicado dizer que essas empresas, ditas sociais, fujam do propósito de acumular capital. Entretanto, dentro do universo das ES definidas pelo governo inglês, existem aquelas condizentes com o campo que se propõe construir no âmbito do ICSEM. Aquelas criadas pelos cidadãos, que sejam autônomas, que produzem, que deem retorno para a comunidade, etc (Defourny \& Nyssens, 2017).

. Para Pestoff e Hulgård (2016), em função dos mecanismos de governança participativa das pequenas cooperativas de produtores, elas se aproximam mais de uma empresa social do que as outras empresas do terceiro setor. O perfil de seus membros mostra a existência de pessoas predispostas a iniciarem ou participarem de atividades em grupo, o que condiz com a proposta do ICSEM. Nesse tipo de organização o trabalho voluntário é mais comum, o que reduz os custos de produção e possibilita maiores investimentos sociais, entretanto os gestores da empresa precisam ter maiores habilidades (Coin, 2016).

Embora não se verifiquem regras, é mais comum identificar empresas sociais em atividades produtivas, especificamente no setor de alimentos. Na Inglaterra, da mesma forma que existem muitas empresas sociais de agricultura, também existe um campo fértil para discussão teórica sobre produção alimentícia. Por exemplo, existem seminários específicos para tratar a sustentabilidade, a segurança, o ativismo e o engajamento cívico em prol da produção de alimentos (Choi \& Graham, 2014). Em geral, estes temas são abordados na perspectiva das empresas sociais e do uso da terra. 
Para se produzir alimentos nas cidades, enfrentam-se muitas barreiras. Entre elas, destacam-se o custo da mão de obra e o preço da terra urbana. A literatura mostra que a lucratividade da agricultura em pequena escala é incompatível com as exigências do mercado capitalista. Por essa razão, os atores que se envolvem com essa atividade precisam ter um perfil diferenciado. Na Inglaterra, emprega-se a participação voluntária dos cidadãos no processo produtivo (Horst, McClintock, \& Hoey, 2017) e, em geral, contabilizam-se experiencias exitosas (Munoz et al., 2015).

O principal retorno da produção de alimentos em áreas urbanas inglesas é social ou ambiental, característica que viabiliza reunir em torno da atividade pessoas colaborativas (Coin, 2016). Além do voluntariado, o estabelecimento de parcerias também é uma estratégia comum entre as empresas sociais do país. Não raro, as organizações que produzem alimentos em áreas urbanas buscam o apoio da comunidade e dos pequenos produtores. Essas ações estão possibilitando, tanto ampliar a área produtiva nas regiões periféricas quanto, aumentar o volume de distribuição nas áreas mais centrais (White \& Bunn, 2017).

Pelas características da agricultura urbana, mesmo considerando que a Inglaterra esteja mudando a sua política de investimentos no setor social (Ridley-Duff \& Bull, 2015), é provável que os projetos relativos à produção de alimentos sejam mantidos. Adicionalmente, a crise globalizada da virada do século levou para os países ricos a ameaça de fome, o que era comum apenas em países pobres. Entre 2005 e 2013, os preços dos alimentos subiram 43\% e a Inglaterra experimentou uma forte crise nesse período. Em 2013 e 2014, o banco público de alimentos serviu mais de 20 milhões de refeições, um recorde indesejável para 0 país (Sonnino \& Hanmer, 2016).

Neste período de crise, o governo aproveita as áreas verdes das cidades para cultivar também a cidadania e facilitar a coesão social (Dennis \& James, 2016). As políticas públicas para produção de alimentos, como o incentivo para criação de mais fazendas comunitárias ou urbanas, estão acontecendo com maior intensidade. Conforme estudos recentes, essas iniciativas não resolvem o problema da alimentação na Inglaterra, mas são uma boa alternativa para o banco de alimentos (Sonnino \& Hanmer, 2016). Além disso, com o apoio do poder público, as empresas sociais estão facilitando a participação voluntária de moradores locais em atividades que beneficiam o ecossistema (Dennis \& James, 2016).

Os grupos sociais envolvidos na produção de alimentos têm facilitado o desenvolvimento de uma visão coletiva baseada na integração entre os objetivos sociais, econômicos e ambientais. A governança das empresas nas quais esses grupos atuam, em geral, pressupõem a participação da comunidade (Dennis \& James, 2016) e a troca de 
saberes. Esse modelo de gestão torna as organizações mais resilientes à medida que os seus projetos são disseminados. Por isso, elas suportam melhor a pressão do mercado e as ausências governamentais. Enfim, essas empresas atendem a algumas das demandas sociais relegadas pelo Estado.

\subsection{Empresas sociais de agricultura urbana no Brasil e na Inglaterra}

A Revolução Industrial alterou a estrutura das cidades tornando-as incompatíveis com a agricultura. A partir daquele período, o espaço urbano deveria se limitar às atividades de planejamento, ao comércio e a indústria (Santos, 1988; Lefebvre, 2013). Ademais, criaram-se meios de transportes mais eficientes, desenvolveram métodos para conservar os alimentos e a produção agrícola já não precisa mais acontecer próximo dos aglomerados humanos. Então, o uso do espaço ganhou novos sentidos, o que afetou a produção de alimentos (Tornaghi, 2017). Com o processo de urbanização, a área destinada à agricultura diminuiu e a atividade perdeu a importância em contexto mundial.

Após mais de um século decorridos da separação entre cidade e produção de alimentos, verificam-se muitas conquistas em prol da reversão desse processo. Nesta década, 15\% do alimento mundial já está sendo produzido em áreas urbanas (Gerster-Bentaya, 2013). Zezza e Tasciotti (2010) verificaram em um estudo global que, em média, mais de 37\% dos citadinos se relacionam com agricultura. Essa atividade representa em torno de $30 \%$ de suas respectivas rendas. Mas, o que se discute para as cidades pós-industriais é a sustentabilidade socioambiental que a agricultura urbana pode proporcionar. Observa-se que a produção agrícola poderia contribuir para aumentar a resiliência das cidades em várias dimensões.

A agricultura urbana se caracteriza pelos pequenos cultivos ou criações em áreas urbanas ou periurbanas e a atividade inclui a produção, o processamento e a distribuição dos alimentos (Mougeot, 2005). No processo produtivo, deve-se aproveitar os recursos, serviços e produtos disponíveis na localidade e os seus resultados devem retornar para a mesma área. Mougeot (2006) descreve um ambiente ideal para que os projetos de agricultura urbana sejam exitosos. Para ele, deve haver o reconhecimento do governo, autossuficiência local incluindo mercado e segurança alimentar, terrenos disponíveis para pobres e ricos e um sistema de compostagem orgânica.

Entretanto, o foco desse trabalho está nas empresas sociais de agricultura urbana. Uma empresa social, independentemente de sua atividade, surge de necessidades da comunidade, prioriza objetivos socioambientais, é autônoma, mantém-se aberta para a 
comunidade e o seu lucro volta para a localidade em que estiver inserida (Evers \& Laville, 2004; Salamon \& Sokolowski, 2016). As atividades agrícolas urbanas condizem com as características das empresas sociais, o que justifica tratar conjuntamente os dois termos em um mesmo campo de estudo.

No âmbito das pesquisas desenvolvidas pelo ICSEM, identificaram-se quatro tipologias para as empresas sociais: 1) empresas sem fins lucrativos que atuam no mercado convencional; 2) cooperativas ou os empreendimentos de economia solidária; 3) empresas tradicionais que realizam negócios sociais; 4) empresas ligadas ao setor público e financiadas pelo governo para executarem serviços de competência do Estado (Defourny \& Nyssens, 2017). As empresas de cada um dos setores da economia clássica constituem matrizes que contêm os modelos supracitados. De acordo com o ICSEM, o conjunto das empresas sociais se constitui a partir de matrizes do primeiro ou do segundo ou do terceiro setor.

A literatura mostrou, para o caso da Inglaterra, que as matrizes dos três setores geram empresas sociais. Nesse caso, o próprio governo cria esses empreendimentos. Além do mais, identificaram-se empresas sociais entre as instituições privadas do setor de mercado e entre aquelas instituições do terceiro setor (Spear et al., 2009). Quanto ao Brasil, ainda não se verificaram empresas sociais provenientes dos dois primeiros setores da economia clássica. Neste caso, identificaram-se empresas sociais apenas na matriz oriunda do terceiro setor, especificamente entre os EES Gaiger et al. (2015). As empresas sociais de agricultura urbana formam um subconjunto a partir do conjunto das empresas sociais dos dois países.

A Figura 1 apresenta um campo de estudos comum ao Brasil e a Inglaterra. Em ambos os casos, a matriz de instituições proveniente do terceiro setor gera empresas sociais. $\mathrm{Na}$ Inglaterra, as empresas sociais de agricultura urbana atendem aos requisitos estabelecidos para as cooperativas sociais. No Brasil, elas obedecem aos mesmos princípios identificados nos empreendimentos de economia solidária. Como os EES brasileiros se assemelham às cooperativas sociais inglesas (Gaiger et al., 2015), é razoável assumir que existe interseção entre os campos.

As matrizes, formadas a partir dos dois primeiros setores da economia clássica, vértices $A$ e $C$ da Figura 1, geram três tipos distintos de empresas sociais na Inglaterra. $A$ quarta e última tipologia identificada pelo ICSEM é comum aos dois países. Nesse universo, empresas sociais provenientes do terceiro setor ou vértice $B$ do triângulo, interessam apenas as empresas sociais de agricultura urbana das cidades de Belo Horizonte e de Londres. $\mathrm{O}$ mapa conceitual, representado pela Figura 1, mostra que as empresas sociais estão na 
interseção dos três ângulos do triângulo $A B C$. No mapa, para verificar o quão social é uma empresa, basta olhar o seu posicionamento relativamente aos vértices do triângulo.

Figura 1 - Mapa conceitual: empresas sociais de agricultura urbana

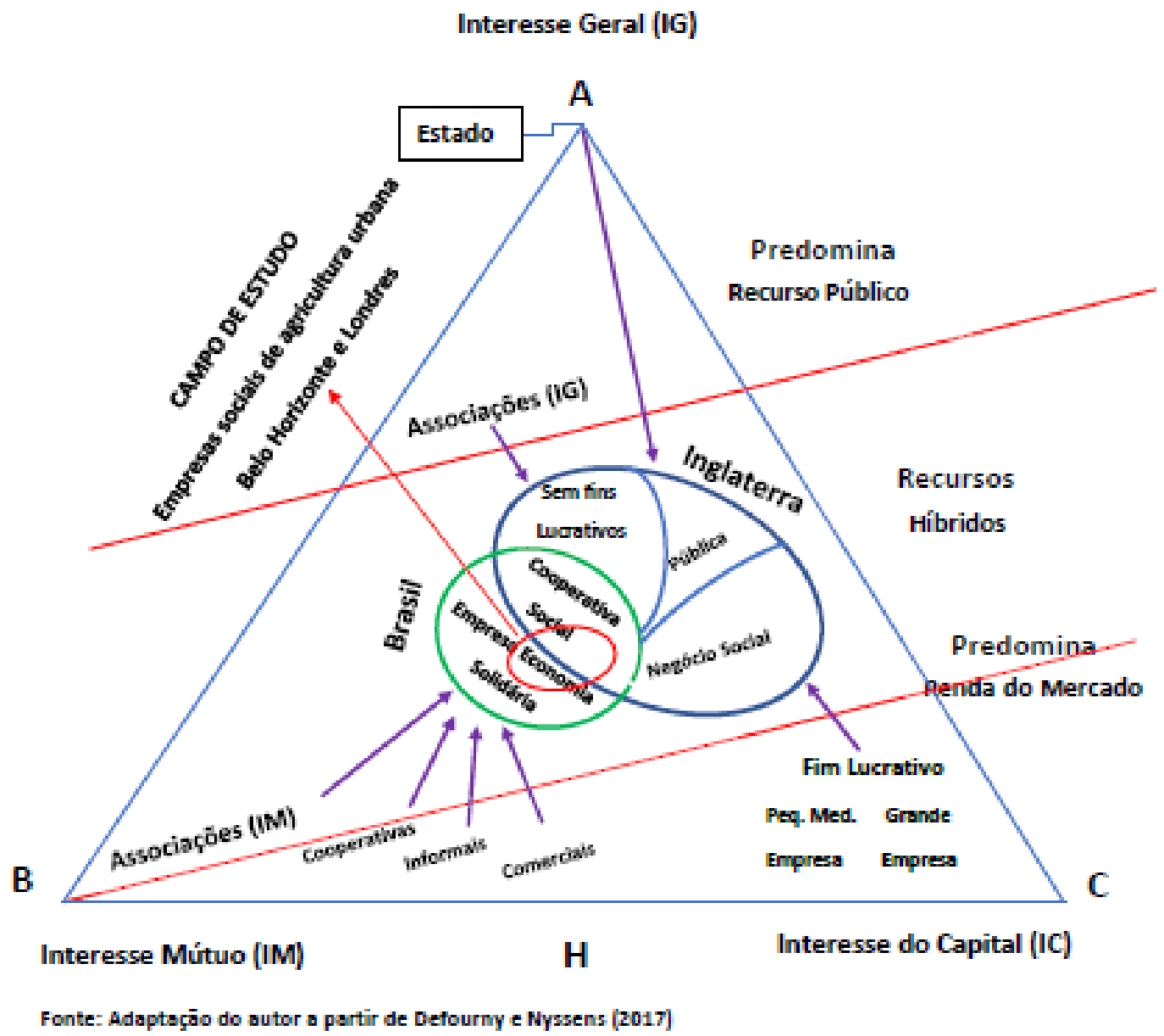

A Figura 1 mostra que as empresas sociais com interesses mais gerais devem ficar próximas do vértice $A$, elas são financiadas pelo governo. Por outro lado, aquelas em que predomina o interesse pelo capital devem se aproximar do vértice $C$. Os seus recursos são captados no mercado. Por fim, aquelas com interesse mútuo devem se aproximar do vértice B. Geralmente, verifica-se em uma mesma empresa social o objetivo de beneficiar toda a comunidade, mas também se verificam nela interesses pessoais. Da mesma forma, uma mesma instituição pode se capitalizar no mercado e receber subsídios do Estado. Assim sendo, a posição da empresa dentro do triângulo diz sobre a sua dimensão social. 


\section{AS POLÍTICAS NEOLIBERAIS NO BRASIL E NA INGLATERRA}

Comparativamente com a Inglaterra, a história do Brasil é muito recente, pois o país se tornou independente de Portugal apenas na primeira metade do século XIX. Por volta de 1890 constituiu-se a Primeira República do Brasil, que durou até 1930. A partir desse período, o presidencialismo brasileiro tem se alternado entre democracia e ditadura. Entre 1930 e 1945, instaurou-se a ditadura do governo Vargas no país. Em seguida, houve 18 anos de democracia, que culminou no golpe de 1964 (Silva, 2014). Após 21 anos de ditadura militar, os cidadãos brasileiros recuperaram o direito de voto. Então, no ano de 1985, iniciou-se o período denominado Nova República que, segundo de Oliveira (2019) perdurou até 2016.

As práticas políticas brasileiras carregam consigo heranças de um período colonial e escravocrata, o que as caracterizam como clientelistas, conservadoras e patrimonialistas. Por essas razões, o regime democrático no país é frágil e, neste caso, os impactos causados pelos modelos de desenvolvimento neoliberais podem ser catastróficos (Maricato, 2017). $\mathrm{Na}$ Inglaterra, com o propósito de fortalecer o neoliberalismo, o governo está criando empresas sociais. Por meio das ES, ele está transferindo para a sociedade as responsabilidades do Estado (Nicholls \& Teasdale, 2017). No Brasil, por outro lado, institucionalizam-se golpes parlamentares para impor uma agenda neoliberal às custas da subtração de direitos sociais (Medeiros \& Lindner, 2017).

Enquanto nos países de democracia densa o povo assume responsabilidades e luta pela manutenção e expansão de seus direitos, nos países de democracia frágil os caminhos para luta são desconhecidos. No cenário brasileiro atual, a maioria da população, quase sempre manipulada pela mídia, está contribuindo para reduzir ou extinguir os seus próprios direitos (Nascimento \& Ferreira, 2019). Mas, essa é uma ação previsível, quando se trata da implantação do neoliberalismo em países de capitalismo periférico. Nesses casos, a desregulamentação do mercado de trabalho e a redução dos direitos sociais configuram como condição para que as agendas de padrão liberal periférico avancem (Filgueiras, 2019).

A reprodução do capital que propicia constituir a dimensão econômico-social em países de capitalismo periférico tem um padrão diferente daquele que se observa nos países de capitalismo central. O capital brasileiro, por exemplo, não se reproduz tendo como base as exportações. O país depende sobremaneira do mercado interno, e quando se fala no aumento das exportações, conforme tem ocorrido nos últimos anos neste país, os produtos em pauta são Comodities. Por essa razão, o Brasil continua subordinado a formação do capital 
imperialista (Filgueiras, 2019). Conforme Revealing (2018), desmatam-se milhões de hectares no Brasil anualmente com o objetivo de produzir soja para alimentar os animais ingleses.

Para a Inglaterra, ou qualquer outro país de capitalismo central, transferir a produção de Comodities para da América Latina, Ásia ou África é um bom negócio (Pimbert \& Moeller, 2018). A partir dessa iniciativa, eles facilitam a reprodução de seus capitais por dedicarem exclusivamente às produções de alto valor agregado, ademais eles se livram do passivo ambiental. Por outro lado, o Brasil lidera o ranking mundial no consumo de agrotóxicos desde 2009, principalmente em função da produção de soja, milho e trigo (Origuéla et al., 2019). Os governos neoliberais brasileiros estão incentivando um modelo agroextrativista que mantem este país submisso àqueles de capitalismo central (Medeiros \& Lindner, 2017).

Nos países de capitalismo periférico, a exportação não se configura como meio para a reprodução do capital. No caso brasileiro, o consumo das famílias determina o movimento da economia, uma vez que noventa porcento de sua produção fica no mercado interno. Por essa razão, quando o salário perde o seu poder de compra, a economia fica estagnada (Dowbor, 2018). O modelo de desenvolvimento neoliberal implica na redução do Estado em detrimento do fortalecimento do mercado. Neste caso, o governo se torna um representante da "burguesia", o que facilita a exploração da força de trabalho e dificulta a ascensão financeira das famílias mais pobres (Filgueiras, 2019). Esta prática intensifica a crise econômica no país.

Observa-se, a partir do exposto, que os países pobres sofrem mais do que os países ricos com a chegada do modelo de desenvolvimento neoliberal (Maricato, 2017). $\mathrm{Na}$ Inglaterra, por exemplo, a população goza de certa autonomia. Eles têm os seus direitos básicos assegurados e os seus salários têm alto poder de compra, o que os tornam menos dependentes do Estado. No caso brasileiro, em função da assimetria na distribuição de renda, sessenta porcento das pessoas sobrevivem com no máximo um salário mínimo mensal, o que os tornam totalmente dependentes dos programas sociais do governo (Arnold, 2018). Então, a redução do Estado atinge frontalmente a maioria das famílias brasileiras.

As políticas neoliberais no Brasil, conforme Dowbor (2018), facilitam a transferência de recursos das famílias para o sistema financeiro, o que impede o desenvolvimento econômico. Ainda como consequência das ações governamentais, principalmente após 2016, deve-se destacar a concentração fundiária, uma vez que houve claro favorecimento do agronegócio e sucateamento da agricultura familiar (Medeiros \& Lindner,2017). Em nome do modelo de desenvolvimento neoliberal, as famílias campesinas brasileiras estão sendo massacradas (Júnior, 2018). Na Inglaterra, as políticas neoliberais também prejudicaram os pequenos produtores, mas eles estão sendo subsidiados pelo governo (Revealing, 2018). 


\section{PROCEDIMENTOS METODOLÓGICOS}

Diante de um cenário em que se verifica o avanço do modelo de desenvolvimento neoliberal, o objetivo desta pesquisa foi verificar como as empresas sociais de agricultura urbana estavam influenciando a resiliência das cidades de Belo Horizonte e de Londres. Em sua estratégia, o pesquisador empregou a abordagem qualitativa e o método do estudo de caso múltiplo (Maffezzolli \& Boehs, 2016). Em Belo Horizonte, investigou-se o Jardim Produtivo (JP) e em Londres o Stamford Hill (SH), ambas as empresas foram constituídas a partir de objetivos sociais. O processo de teorização neste trabalho se deu, prioritariamente, pela descrição contextualizada dos casos de estudo (Eisenhardt, 1989).

As principais fontes de evidências utilizadas nesta pesquisa foram a observação direta e a entrevista (Bauer \& Gaskell, 2010). No caso londrino, o pesquisador visitou a empresa SH nos meses de julho de 2015, julho de 2016 e no segundo semestre de 2017. Durante essas visitas, além da observação direta, entrevistaram-se a criadora do projeto que originou o $\mathrm{SH}$ e um dos cidadãos envolvidos com o empreendimento. Adicionalmente, no ano de 2017, o pesquisador participou de uma reunião com um dos representantes do poder público Inglês. A pauta do evento estava relacionada com os critérios governamentais que se empregam para ocupação de áreas públicas com a produção agrícola naquele país.

As fontes documentais também foram expressivas no processo da coleta de dados. $\mathrm{Na}$ Inglaterra, recorreu-se a legislação e aos documentos que possibilitaram compreender a trajetória da agricultura urbana no país. O SH faz parte dessa história, embora esse empreendimento tenha surgido a partir de uma iniciativa privada. No Brasil, a empresa social JP nasceu no arcabouço de um projeto maior que foi articulado pelo governo, por organizações da sociedade civil, por instituições internacionais e pela comunidade. Por essa razão, o caso gerou uma série de publicações científicas que facilitaram a documentação de todas as fases do empreendimento.

No JP, o pesquisador realizou o trabalho de campo no ano de 2016. Além das visitas ao local com objetivo de observar as práticas dos agricultores, o pesquisador também entrevistou os atores envolvidos no projeto. Entre os entrevistados, destacou-se uma das agriculturas que participaram da fundação da empresa, um casal de produtores que já estava trabalhando na unidade produtiva a um ano, dois consumidores e quatro membros da comunidade. Adicionalmente, o pesquisador participou dos movimentos sociais que deram origem ao projeto. Nessas oportunidades, ele interagiu com agentes do poder público, com membros da Universidade Federal de Minas Gerais e com organizações da sociedade civil. 
O uso de múltiplas fontes de evidências facilitou a triangulação dos dados coletados ao longo da pesquisa (Yin, 2005). Na Seção 6, discutem-se os resultados verificados na literatura em conjunto com trechos de entrevistas e com os elementos do diário de campo. Motivado pela necessidade de compreender como as empresas sociais JP e SH estavam influenciando a resiliência de Belo Horizonte e de Londres, o autor se orientou para apresentar as suas conclusões. Na Seção 5, apresenta-se uma breve descrição da empresa belohorizontina e da empresa londrina. Essa parte do texto corrobora a discussão dos resultados e a conclusão proporcionada pelo trabalho que se realizou com os dados.

\section{DESCRIÇÃO DAS UNIDADES DE ANÁLISES}

No Brasil, a agricultura urbana surgiu conjuntamente com as cidades, entretanto, o tema entrou para a agenda governamental só na década de 1990. No âmbito das cidades brasileiras, a agricultura é tratada no campo da Segurança Alimentar Nutricional (SAN). O Conselho Nacional de Segurança Alimentar (CONSEA), criado na década de 1990, é o órgão que impulsiona as discussões sobre este tema no país. Entretanto, os conselhos populares dependem da estabilidade no cenário político, o que dificulta efetivar as ações de interesse das comunidades. Apesar dos entraves, Belo Horizonte foi uma das primeiras cidades do país a discutir agricultura urbana na perspectiva legal (Silva, 2014; De Moura \& de Almeida, 2017).

$\mathrm{Na}$ Inglaterra, a agricultura urbana está entre as preocupações dos governantes há muitas décadas. Desde 1908, conforme Campbell et al. (2011), as autoridades do país já se comprometem em alocar pequenos lotes urbanos para o exercício de atividades agrícolas. $\mathrm{O}$ próprio Estado garante aos cidadãos o direito de plantar, uma vez que ele detém $94 \%$ das propriedades urbanas destinadas ao cultivo (Clatworthy et al., 2017). Desde 1930, a empresa sem fins lucrativos National Society of Allotment and Leisure Gardeners (NSALG) promove a interlocução entre sociedade e Estado. O objetivo da NSALG é promover a gestão do uso da terra e garantir a produção agrícola urbana (Garnett, 2000).

\subsection{Unidade de análise Jardim Produtivo - Belo Horizonte}

A unidade de análise Jardim Produtivo surgiu como um desdobramento da Conferência Eco - 92, evento sobre o meio ambiente promovido pela Organização das Nações Unidas (ONU) na cidade do Rio de Janeiro em 1992. Em função da agenda definida nesse evento, em 1995, a prefeitura de Belo Horizonte projetou construir para a cidade quatro 
Centros de Vivência Agroecológicas (CEVAE). Entretanto, o Município tinha dotação orçamentária para fazer só três dos quatro centros projetados, o que o fez buscar recurso externo para financiar o restante das obras. Em decorrência das relações estabelecidas na Eco - 92, a prefeitura recebeu apoio financeiro do Fundo Life/PNUD/ONU (Lovo, 2011).

Para fazer o aporte dos recursos, o financiador internacional exigiu que o poder público se articulasse com organizações da sociedade civil, essa foi uma condição para que a instituição liberasse a verba complementar do projeto. A necessidade da prefeitura foi de encontro aos anseios da Rede de Tecnologias Alternativas (Rede - MG), pois ambos desejavam fomentar a agricultura na cidade. A Rede - MG é uma organização não governamental (ONG) que nos anos 90 já atuava em prol de causas socioambientais no Estado. Então, a partir de interesses mútuos, a prefeitura, a ONG e o fundo Life/PNUD/ONU se tornaram parceiros para construir os CEVAEs (Borges, 2013).

Criaram-se os CEVAEs para funcionarem como multiplicadores que reforçariam o auto abastecimento para as famílias de baixa renda da capital. Eles complementariam as ações dos programas de hortas comunitárias, hortas escolares e pomares. Tratavam-se de equipamentos públicos comunitários que visavam resguardar a segurança alimentar e a saúde da população mais pobre de Belo Horizonte, além de promover a educação ambiental, a capacitação profissional e a geração alternativa de renda. Ademais, a gestão dessa empresa deveria ser descentralizada e participativa. Os CEVAEs configuraram como caso de sucesso por quase cinco anos (Lovo, 2011).

Os parceiros supracitados firmaram um convênio para desenvolver o projeto dos CEVAEs em 1995 e a parceria se manteve formalizada por cinco anos. Ao longo desse período, o projeto funcionou muito bem, o que garantiu a Belo Horizonte projeção internacional. Mas, no ano de 2005, em função de descontinuidades na política, as unidades de produção dos CEVAEs já estavam bem deterioradas (Borges, 2013). Mesmo assim, os atores envolvidos no projeto perceberam potencialidades para a agricultura urbana na capital. Por essa razão, eles decidiram realizar novos investimentos na atividade, mas fizeram adequações no projeto que estava em curso.

No ano de 2007, como parte de um programa global que contemplou 18 cidades no mundo, realizaram-se em Belo Horizonte um levantamento sobre agricultura urbana. A fundação Resource Centre on Urban Agriculture e Food Security (RUAF), sediada na Holanda, financiou a pesquisa. Os resultados positivos do trabalho propiciaram à prefeitura, em conjunto com a Rede - MG, a aprovação de novos aportes para os projetos agrícolas da cidade. Então, financiados pelo programa Cities Farming for the Future (CFF), eles investiram 
parte dos recursos na revitalização daquele CEVAE que poderia dar certo e construíram um novo projeto denominado Jardim Produtivo (Lovo, 2011).

Ao planejarem a execução do Jardim Produtivo (JP), eles objetivaram desvincular o novo projeto das hortas urbanas convencionais da cidade. Para eles, o modelo tradicional de produção urbana já havia se desgastado com as tentativas precedentes. Essa empresa social de agricultura urbana foi criada para servir como referência para outros projetos. Conforme Coutinho (2010), o objetivo principal do empreendimento seria a socialização dos moradores da comunidade, mas admitia-se a possibilidade de produção com objetivos comerciais. Além disso, de acordo com Lovo (2011), o projeto melhoraria a segurança alimentar na região e produziria benefícios ambientais para a cidade.

Concebeu-se a empresa no ano de 2007com o propósito de capacitar 21 produtores e beneficiar diretamente 15 famílias da região. Utilizou-se "o interesse pela atividade" como critério principal para identificar os beneficiários do projeto (Lovo, 2011). Em 2009, trabalharam nessa unidade produtiva, em média, 9 pessoas. Em 2012, atuaram em média 6 pessoas na horta. Nesse período, o objetivo principal dos horticultores era comercial, entretanto a atividade não representava a renda principal para eles. Quase todos estavam recebendo benefício do governo e todos haviam migrado do campo para a capital (Borges, 2013).

Construíram-se o JP em um bairro periférico da capital. A unidade ocupa um terreno de propriedade pública que mede $3.500 \mathrm{~m}^{2}$. Esse empreendimento foi projetado para ocupar um vazio urbano, sobra de terra proveniente da construção de um conjunto habitacional. A área destinada a produção foi subdividida em canteiros. Cada horticultor se apossa de áreas que variam de $100 \mathrm{~m}^{2}$ a $400 \mathrm{~m}^{2}$, ainda assim o JP fica subocupado em grande parte do tempo. O espaço é totalmente demarcado e cercado (Borges, 2013). As vias que contornam o terreno são todas pavimentadas. Embora o bairro seja arborizado, a área de cultivo se destaca pela presença do verde e dá diversidade produtiva.

\subsection{Unidade de análise Stamford Hill - Londres}

Culturalmente, os londrinos têm uma forte relação com o uso da terra. Há mais de 300 anos, na era Elizabethan, a rainha já compensava os excluídos do campo com pequenos terrenos na capital (Abele et al., 2016). Desde o início do século XX, a distribuição de áreas urbanas para cultivo está regulamentada no país, mas não existe espaço para todos aqueles que o desejam. Neste século, mais de cem mil pessoas esperam por uma área de cultivo em 
Londres (Campbell et al., 2011). Uma parte da população dessa cidade possui quintal em casa para plantar, mas a maioria vive em apartamentos. Estes últimos reivindicam o direito de produzir e o governo reconhece esse direito ao distribuir os lotes (Clatworthy et al., 2017).

Mesmo considerando que o poder público converte 831 ha da área de Londres em lotes para plantios, a demanda reprimida ainda é grande entre os cidadãos. Aos governantes do país não restam dúvidas, o investimento em agricultura urbana minimiza os gastos com doenças, reduz as milhas alimentares e deixa a cidade mais agradável (Mok et al., 2014). Ainda assim, diante da necessidade de expandir o número de moradias (Prayag et al., 2013; Oakland, 2015), o próprio governo não consegue atender a todo o cidadão que precisa de um pequeno terreno para plantar. Mas, além das áreas públicas, existem outros espaços urbanos que podem ser utilizadas para a produção de alimentos (Garnett, 2000).

A empresa privada What if: projects, um pequeno escritório de arquitetura inglês, negociou espaços ociosos privados de Londres para produção agrícola. A empresa social Stamford Hill, objeto de estudo neste trabalho, ocupa um desses espaços. O objetivo do projeto, denominado Vacant Lot; compreendia entregar para a comunidade 21 áreas de cultivos em bairros centrais da cidade. O seu público alvo eram os pobres urbanos, aqueles que moravam em pequenos apartamentos subsidiados pelo governo. O projeto visava, além de produzir alimentos para as famílias, transformar as áreas inúteis, esquecidas e sujas do entorno dos prédios em lugares agradáveis para se ver e viver (Feireiss \& Hamm, 2015).

A concepção do projeto partiu de uma intervenção artística que a empresa realizou no Festival de Shoreditich em Hoxton, no ano de 2007. A What if: projects transformou uma área de $290 \mathrm{~m}^{2}$ em 72 lotes de $1 \mathrm{~m}^{2}$ permeados por espaços vazios destinados a circulação. Esses lotes estavam em um lugar de grande visibilidade e chamaram a atenção pela diversidade de culturas alimentícias que estavam produzindo. Inicialmente, o objetivo seria construir um espaço bonito, agradável, barato e que pudesse ser removido facilmente, pois a empresa pretendia desmontar o cenário após o evento. Entretanto, a comunidade local se manifestou favorável a permanência da área de cultivo naquele espaço.

Os moradores de Shoreditich assumiram a responsabilidade de manutenção da horta com o apoio do poder público e do proprietário do terreno. Após dois anos, a What if: projects constatou que o cultivo havia se tornado autossustentável, o que a motivou investir no Vacant Lot. Então, no ano de 2009, eles iniciaram a construção de mais 20 unidades em Londres. Em 2012, ao colocarem mesas e bancos entre os canteiros, a empresa finalizou a sua primeira unidade de produção em Hoxton. Nesse mesmo ano, ela entregou à comunidade de Camden 
21a horta. Após concluir o projeto, incluindo curso de capacitação para os usuários da terra, eles transferiram a gestão do negócio para as comunidades (Ehmann et al, 2012).

A What if: projects desenvolveu o projeto Vacant Lot com objetivos sociais. Nesse caso, nenhuma das famílias beneficiadas pelas áreas produtivas tiveram que pagar pelos serviços ou produtos. Para isso, além da empresa fazer investimento próprio, ela contou com pelo menos três parceiros importantes. A Big Lottery concedeu recursos para a compra de materiais, a instituição de caridade ambiental Groundwork identificou as comunidades beneficiárias e os gestores das moradias sociais cederam o terreno para o plantio. Ademais, a participação da comunidade na edificação das áreas de cultivo foi determinante. Eles atuaram, mesmo sem saber quem seria contemplado com o terreno, em todo o processo.

Em geral, o projeto Vacant Lot beneficiou diretamente mais de 850 famílias de 21 conjuntos habitacionais de áreas consideradas pobres em Londres. Em particular, a horta comunitária Stamford Hill está sendo utilizada por 42 famílias da região de Hackney. A área utilizada para a sua construção possui $490 \mathrm{~m}^{2}$ e cada um dos usuários da horta cultiva em 1,2 $\mathrm{m}^{2}$. Depois que o empreendimento foi entregue aos moradores em 2012, eles assumiram completamente a gestão do espaço. Ou seja, os próprios horticultores se encarregam dos custos da atividade e se beneficiam de seus resultados (Feireiss \& Hamm, 2015).

O empreendimento está incrustado em uma região totalmente urbana da cidade, são prédios residenciais e trânsito de automóveis por todos os lados. Por se tratar de produção orgânica, a horta não permanece completamente limpa. Pois, nesse tipo de plantação, a existência de mato entre os alimentos reduz a incidência de pragas (Ehlers, 2017). Contudo, o aspecto é de um jardim bem arquitetado. Canteiros elevados com madeira, casa de ferramentas e utensílios seguindo o padrão arquitetônico da região e muita decoração funcional. Entre os itens de decoração, destacam-se um espantalho e aviões confeccionas com garras pets. Eles são funcionais por protegerem as plantas das pragas e pássaros.

O número de moradores do condomínio que se interessam pela atividade, geralmente é bem maior do que o número de lotes disponíveis. Por essa razão, eles próprios articulam um revezamento para usar o espaço. Todos os lotes são totalmente produtivos, mas cada usuário dispõe apenas de $1 \mathrm{~m}^{2}$. Então, eles plantam itens diferentes e trocam entre eles verduras e legumes. A comercialização do excedente in natura no mercado próximo acontece esporadicamente, entretanto, o mais comum é o beneficiamento dos produtos. Eles promovem cursos de culinária na própria horta e vendem bolos e chás feitos com ingredientes do lugar. Embora a empresa gere receita, esse está longe de ser o seu objetivo principal. 


\section{DISCUSSÃO DOS RESULTADOS}

O trabalho de campo mostrou que as atividades desenvolvidas, tanto no Jardim Produtivo (JP) quanto no Stamford Hill (SH), se caracterizam como agricultura urbana, conforme Mougeot (2005). Em ambos os casos, as empresas produzem hortaliças em áreas urbanas e o retorno da atividade fica nas comunidades em que elas se inserem. No Brasil, o JP atua na periferia de Belo Horizonte. Na Inglaterra, o SH atua em uma região nobre de Londres, mas está na área de um conjunto habitacional pobre. O SH produz, beneficia e distribui os seus produtos, porém em quantidades mínimas. O JP produz em maior quantidade, mas a empresa não beneficia os produtos antes de distribuir.

As duas empresas de agricultura urbana, conforme descrito pela teoria de Mougeot (2006), tem grande probabilidade de sucesso. Ambas aproveitam recursos e serviços disponíveis na localidade. Conforme entrevistas dos horticultores do JP, o adubo de origem animal provem de fazendas próximas do cultivo e o adubo de origem vegetal é produzido por eles próprios. Em entrevista, a proponente do projeto SH disse que os horticultores aproveitam o resíduo da própria horta como adubo, mas a quantidade é insuficiente. Então, eles precisam comprar na vizinhança o adubo complementar. Ela acrescentou que a produção do adubo ainda é um problema para o SH. Ambas as empresas contam apenas com mão de obra local.

Ainda de acordo com Mougeot (2006), outro fator determinante de sucesso para uma empresa de agricultura urbana é o apoio governamental. O JP se constituiu a partir da iniciativa governamental e de recursos públicos. No caso do $\mathrm{SH}$, o mérito relativo à sua implantação é de uma empresa privada, mas o projeto recebeu financiamento público, através da Big Lottery. Além disso, as empresas deveriam ser autossuficientes localmente e prezar pela segurança alimentar. Por se tratar de produção agroecológica, não há problemas quanto a segurança alimentar e ambiental (Schneider \& Zanelli, 2017). Por outro lado, o JP encontra dificuldades em acessar o mercado e o SH ainda não é capaz de produzir o seu próprio adubo orgânico, esses são os seus pontos fracos.

Tanto o JP quanto SH, de acordo com a teoria discutida no âmbito do ICSEM (Gaiger et al., 2015; Defourny \& Nyssens, 2017), são consideradas como empresas sociais. Observou-se que ambas surgiram a partir de necessidades da comunidade. Pois, antes de implantarem o JP, realizaram-se um estudo detalhado para levantar as necessidades da comunidade que receberia o projeto (Borges, 2013). No caso do SH, conforme entrevista da gestora do Vacant Lot, a instituição Groundwork se encarregou de identificar as comunidades que mais estariam necessitando de uma empresa social de agricultura. 
Quanto a autonomia, outra característica de uma empresa social, as duas instituições possuem liberdade de ação. Nenhuma delas contraíram dívidas com empresas ou financiadores, por essa razão elas promovem a gestão de seus negócios sem influências externas. Adicionalmente, é desejável que essas empresas permaneçam abertas para a comunidade. A partir da entrevista que se realizou com uma das horticultoras mais antigas do $\mathrm{JP}$, verificou-se que a empresa estava aberta para qualquer membro da comunidade que se interessasse pelo plantio, pois a entrevistada afirmou que havia canteiros disponíveis na horta. No $\mathrm{SH}$, o pesquisador viu as regras para inserção da comunidade estampadas na empresa.

Por fim, tanto o JP quanto o SH retornam para a própria comunidade os resultados da produção. No caso brasileiro, alguns dos produtores abastecem escolas públicas locais, outros vendem as hortaliças para os membros da própria comunidade. No caso inglês, a maior parte da produção é para o consumo próprio. Uma parte do excedente é processado e negociado na própria horta com os moradores do condomínio. A outra parte é vendida no comércio local.

Ao considerar o campo de estudo, aquele definido na Figura 1 a partir do modelo proposto pelo ICSEM, observou-se diferenças básicas entre as origens das empresas. O JP, contrariando o previsto pelo modelo teórico, foi gerado no primeiro setor da economia clássica. Quem propôs e financiou o negócio foi o poder público. Quanto a empresa britânica, não houve surpresas. Os três setores econômicos da Inglaterra geram empresas sociais. O SH nasceu a partir da iniciativa de uma empresa do setor de mercado. Mas, nos dois casos, o terceiro setor foi decisivo no processo de criação das empresas. No Brasil, ele viabilizou recursos internacionais. Em Londres, uma empresa do terceiro setor identificou famílias para o projeto.

A fragilidade do regime democrático e a instabilidade política brasileira (Oliveira, 2019; Maricato, 2017) retardaram a consolidação das leis de agricultura urbana e de empresas sociais no país. Possivelmente, em função das diferenças entre Brasil e Inglaterra nessa perspectiva, observaram-se resultados mais efetivos no SH do que JP. Enquanto investiramse menos de 7 mil euros no SH, o investimento no JP superou 170 mil euros. Mesmo assim, enquanto o $\mathrm{SH}$ beneficia diretamente 42 famílias, o JP beneficia uma média de 10 famílias. Para o caso brasileiro, levantaram-se os dados a partir do trabalho de Lovo (2011) e para o caso inglês, o valor do investimento no projeto foi declarado pela sua gestora em entrevista.

O avanço do modelo de desenvolvimento neoliberal no Brasil (Filgueiras, 2019) é um fator marcante na trajetória do JP. Com a redução do tamanho do Estado, o trabalhador perde os seus direitos e o poder de compra dos salários reduz. Por essas razões, a comunidade se 
torna cada vez mais dependente de políticas públicas. As entrevistas dos horticultores do JP mostraram que o número de trabalhadores da horta depende diretamente dos empregos que o mercado formal gera. Quando aumenta a oferta de trabalho sobram canteiros no JP, da mesma forma, quando aumenta o desemprego, faltam espaços para trabalho no JP. Embora o neoliberalismo esteja avançando na Inglaterra também, o SH não mostrou esse efeito.

As políticas neoliberais no Brasil fomentam o agro extrativismo que, por consequência demanda a expansão do uso de agrotóxicos (Origuéla et al., 2019). As consequências dessas políticas para o JP são claras. O volume de pragas cresce e os produtores encontram mais dificuldades para combate-las. Além disso, não se encontram facilmente sementes orgânicas em Belo Horizonte. Os horticultores são obrigados a usar os produtos transgênicos que as grandes indústrias do agronegócio disponibilizam no mercado. Em Londres, os produtores do $\mathrm{SH}$ encontram as sementes orgânicas que precisam com facilidade e eles não enfrentam em suas hortas a diversidade de pragas que são inevitáveis nos plantios brasileiros.

\section{CONSIDERAÇÕES FINAIS}

A pesquisa mostrou que o JP e SH se tornaram resilientes, uma vez que estas empresas sociais estão resistindo em ambientes cujo capitalismo é hegemônico. Como o processo de constituição desses empreendimentos lhes garantiram habilidades para resolver problemas, eles estão contribuindo para que as cidades, tanto Belo Horizonte quanto Londres, aumentem as suas capacidades de adaptação diante das mudanças impostas pelo avanço do neoliberalismo. Ambos os casos estão influenciando positivamente as suas cidades, mas os produtos oferecidos pelo JP são diferentes daqueles ofertados pelo $\mathrm{SH}$.

No caso belo-horizontino, um reflexo imediato do avanço do modelo de desenvolvimento neoliberal é a redução do poder de compra dos salários e o aumento do desemprego. Relativo a esses pontos, o JP oferece possibilidades para que os moradores da comunidade ganhem algum dinheiro. Ademais, os produtos agroecológicos no mercado desta capital são escassos. Assim sendo, a empresa preenche a lacuna deixada pelo setor de mercado em sua comunidade. Embora o JP tenha surgido no âmbito do primeiro setor, a empresa não tem suporte legal para se desenvolver. Por essa razão, ela faz menos do que poderia fazer pela sua comunidade.

No SH a dimensão financeira do negócio tem um peso bem menor do que teria se ela estivesse no Brasil. Por outro lado, a empresa aumentou a segurança e melhorou a aparência de sua região, uma vez que ocupou um terreno baldio. Esse benefício valoriza todo o entorno 
da unidade produtiva. Conforme os entrevistados, a horta funciona como uma extensão de suas casas e se tornou um espaço de convivência para os moradores da comunidade. Ela se tornou um meio de entretenimento, facilita a socialização entre os moradores e reduz a probabilidade de doenças como o estresse. Destacam-se ainda uma melhora no meio ambiente e redução das milhas alimentares.

A principal limitação deste estudo foi a impossibilidade de pesquisar um número maior de casos, principalmente no Brasil. Os esforços realizados pelos acadêmicos do ICSEM com objetivo de definir empresas sociais, até o momento, mostraram apenas uma fração do terceiro setor como gerador dessa modalidade de empresas no Brasil. O que justifica essa restrição, é a falta de pesquisas empíricas no país. Esse trabalho mostrou que o primeiro setor da economia clássica também gera empresa social no Brasil. Então, a partir deste resultado, recomenda-se que outras pesquisas no âmbito das empresas sociais de agricultura urbana sejam realizadas. Assim sendo, criam-se oportunidades para que outros setores da economia brasileira apareçam como geradores de empresas sociais.

\section{Referências}

Abramovay, R. (2016). A heurística do medo, muito além da precaução. Estudos Avançados, 30(86), 167-179.

Abele, F., Comninel, G., \& Meiksins, P. (2016). Socialism and democracy: the political engagements of Ellen Meiksins Wood. Studies in Political Economy, 97(3), 320-336.

Agostini, M. R. (2016). Correlações entre diferentes terminologias no contexto do terceiro setor: Inovação social x Empreendedorismo social x Empresa social x Negócio social. In Anais do Congresso Brasileiro de Estudos Organizacionais.

Arnold, J. M. (2018). Construindo um Brasil mais próspero e mais produtivo.

Bauer, M. W., \& Gaskell, G. (2010). Pesquisa qualitativa com texto, imagem e som: um manual prático. In Pesquisa qualitativa com texto, imagem e som: um manual prático. Vozes.

Besley, T., \& Ghatak, M. (2017). Profit with purpose? A theory of social enterprise. American Economic Journal: Economic Policy, 9(3), 19-58.

Bombardi, L. M. (2017). Geografia do uso de agrotóxicos no Brasil e Conexões com a União Europeia. São Paulo: FFLCH - USP

Borges, K. A. D.. A experiência da agricultura urbana na RMBH: desenvolvimento empoderamento local. 2013. 206f. Dissertação de mestrado - Universidade Católica de Minas. Disponível em: < https://docs.google.com/file/d/0B6xCNrU_EfzgeW13Vy1LNj N0T1E/edit?usp=sharing\&pli=1> Acesso em: 28 out. 2013. 
Borges, W. C., Júnior, T. P., Ambrozini, M. A., \& Sanches, L. B. (2018). O impacto da crise financeira internacional de 2008 sobre a estrutura de capital das empresas de países desenvolvidos e emergentes. Revista Contemporânea de Contabilidade, 15(34), 58-75.

Campbell, M., Campbell, I., \& Kirby, T. T. W. (2011). Allotment waiting lists in England 2011. Transition Town West Kirby, National Society of Allotment and Leisure Gardeners, United Kingdom.

Choi, J. H. J., \& Graham, M. (2014). Urban food futures: ICTs and opportunities.

Clatworthy, J., Hinds, J., \& Camic, P. M. (2017). Exploring the Relationship between Suburban Allotment Gardening and Well-Being: An Interpretative Phenomenological Analysis. Ecopsychology, 9(3), 121-129.

Coin, I. (2016). Learning about Land.

DAROLT, M. R. (2012). Conexão ecológica. Curitiba: IAPAR

de Andrade Silva, A. P., \& Gonçalves-Dias, S. L. F. (2015). MENSURAÇÃO DE DESEMPENHO SOCIOAMBIENTAL: ESTUDO DE CASOS EM NEGÓCIOS SOCIAIS BRASILEIROS. Pensamento \& Realidade. Revista do Programa de Estudos Pós-Graduados em Administração-FEA. ISSN 2237-4418, 30(2).

de Moura Costa, H. S., \& de Almeida, D. A. O. (2017). AGRICULTURA URBANA: possibilidades de uma praxis espacial?. Cadernos de Estudos Culturais, 4(08)

De Oliveira Trecha, C., Lovatto, P. B., \& Mauch, C. R. (2017). Entraves do cultivo convencional e as potencialidades do cultivo orgânico do pimentão no Brasil. Revista Thema, 14(3), 291-302.

de Oliveira, R. P. (2019). A DEBACLE DA NOVA REPÚBLICA BRASILEIRA: DA DESILUSÃO AO ENCERRAMENTO DE UM CICLO DEMOCRÁTICO. Revista Espirales, 2(3), 25-42.

de Souza PRATES, C., de CASTRO, M. C. G., LUNAS, D. A. L., \& CASTRO, J. D. A. B. (2016). Economia solidária como política pública para combate ao desemprego: Implicações para agricultura brasileira. Revista ESPACIOS| Vol. 37 (№ 19) Año 2016.

Defourny, J., \& Nyssens, M. (2017). Fundamentals for an international typology of social enterprise models. VOLUNTAS: International Journal of Voluntary and Nonprofit Organizations, 28(6), 2469-2497.

Diniz, R. F., Neto, C. D. C. N., \& Hespanhol, A. N. (2016). A EMERGÊNCIA DOS MERCADOS INSTITUCIONAIS NO ESPAÇO RURAL BRASILEIRO: AGRICULTURA FAMILIAR E SEGURANÇA ALIMENTAR E NUTRICIONAL. Geo UERJ, (29), 234-252.

Dowbor, L. (2018). A era do capital improdutivo: Nova arquitetura do poder-dominação financeira, sequestro da democracia e destruição do planeta. Editora Autonomia Literária LTDA-ME.

DTI, (2002) Social Enterprise: A Strategy for Success, London: Department for Trade and Industry.

Durand, J. D. (1977). Historical estimates of world population: an evaluation. Population and Development Review, 253-296. 
Eckert, D. (2016). A mercantilização em contramovimento: relações de reciprocidade e coesão social na agricultura sustentada pela comunidade em Minas Gerais.

Ehlers, E. M. (2018). Turismo sustentável: oportunidade de empreendedorismo e conservação ambiental. Boletim Técnico do Senac, 30(1), 28-37.

Ehmann, S., Bohle, S., \& Klanten, R. (Eds.). (2012). Cause and effect: visualizing sustainability. Gestalten

Eisenhardt, K. M. (1989). Building theories from case study research.Academy of management review, 14(4), 532-550.

Evers, A., \& Laville, J. L. (Eds.). (2004). The third sector in Europe. Edward Elgar Publishing.

Feireiss, K., \& Hamm, O. G. (2015). Transforming cities. Urban interventions in public space, Berlin, Jovis.

Filgueiras, L. A. M. (2019). PADRÃO DE REPRODUÇÃO DO CAPITAL E CAPITALISMO DEPENDENTE NO BRASIL ATUAL. Caderno CRH, 31(84), 519-534.

Furtado, A. F., de Sousa Teodósio, A. D. S., \& do Carmo Guerra, J. F. (2017). Empresas Sociais na promoção do Desenvolvimento Local: avanços e armadilhas em Brumadinho/Minas Gerais. Revista de Administração, Contabilidade e Economia da Fundace, 8(3).

Gaiger, L. I. (2015). A economia solidária na contramarcha da pobreza. Sociologia, Problemas e Práticas, (79), 43-63.

Gallo, Z., Martins, L. A. D. T. P., \& Peres, M. T. M. (2016). Pobreza, meio ambiente e economia solidária: o caso de Piracicaba. Revista da FAE, 8(1).

Garnett, T. (2000). Urban agriculture in London: rethinking our food economy.Growing Cities, Growing Food. German Foundation for International Development, Feldafing, Germany, 477-500.

Gerster-Bentaya, M. (2013). Nutrition-sensitive urban agriculture. Food security, 5(5), 723737.Gerster-Bentaya, M. (2013). Nutrition-sensitive urban agriculture. Food security, 5(5), 723-737

Horst, M., McClintock, N., \& Hoey, L. (2017). The intersection of planning, urban agriculture, and food justice: a review of the literature. Journal of the American Planning Association, 83(3), 277-295.

Jahchan, A. L., Comini, G. M., \& D'Amario, E. Q. (2016). Negócios sociais: a percepção, a consciência e o grau de interesse pelo tema para os alunos de graduação em administração. Administração: Ensino e Pesquisa, 17(3), 537-566.

Jegers, M. (2008). Managerial economics of non-profit organizations. Routledge.

Kerstenetzky, C. L., \& Guedes, G. P. (2018). O Welfare State resiste? Desenvolvimentos recentes do estado social nos países da OCDE. Ciência \& Saúde Coletiva, 23, 2095-2106.

Klug, L. B. (2018). Resiliência e ecologia urbana.

Laville, J. L. (2014). Mudança social e teoria da economia solidária. Uma perspectiva maussiana. Sociologias, 16(36). 
Laville, J. L., \& Nyssens, M. (2001). 18 The social enterprise Towards a theoretical socioeconomic approach. 132.

Lefebvre, H. (2013). Preface: the production of space. Estudos Avançados,27(79), 123-

Lovo, I. C. (2011). Agricultura urbana: um elo entre o ambiente e a cidadania.

Maffezzolli, E. C. F., \& Boehs, C. G. E. (2016). Uma reflexão sobre o estudo de caso como método de pesquisa. Revista da FAE, 11(1).

Maffezzolli, E. C. F., \& Boehs, C. G. E. (2016). Uma reflexão sobre o estudo de caso como método de pesquisa. Revista da FAE, 11(1).

Maricato, E. (2017). O impasse da política urbana no Brasil. Editora Vozes Limitada.

Medeiros, R. M. V., \& Lindner, M. (2017). Dinâmicas do espaço agrário: velhos e novos territórios: NEAG 10 anos.

Mok, H. F., Williamson, V. G., Grove, J. R., Burry, K., Barker, S. F., \& Hamilton, A. J. (2014). Strawberry fields forever? Urban agriculture in developed countries: a review. Agronomy for sustainable development, 34(1), 21-43

Mougeot, L. J. (2005). Neglected issues on form and substance of research on urban agriculture. AGROPOLIS. The social, political and environmental dimensions of urban agriculture, 267-279.

Mougeot, L.J.A. (2006): Growing better cities - Urbam Agriculture for Sustainable Development, IDRC.

Mswaka, W. (2015). Scenario planning in social enterprises; the case of South Yorkshire. International Journal of Foresight and Innovation Policy.

Munoz, S. A., Farmer, J., Winterton, R., \& Barraket, J. (2015). The social enterprise as a space of well-being: an exploratory case study. Social Enterprise Journal, 11(3), 281-302.

Nascimento, G. M., \& Ferreira, M. R. (2019). UMA RESENHA CRÍTICA ACERCA DO LIVRO DESERTIFICAÇÃO NEOLIBERAL NO BRASIL, DE RICARDO ANTUNES. Revista Culturas Jurídicas, 5(12).

Nicholls, A., \& Teasdale, S. (2017). Neoliberalism by stealth? Exploring continuity and change within the UK social enterprise policy paradigm. Policy \& Politics, 45(3), 323-341.

Oakland, J. (2015). British civilization: an introduction. Routledge.

Origuéla, C. F., de Freitas Coca, E. L., \& Pereira, L. I. (2019). Compreendendo o avanço do neoliberalismo na agricultura através do debate paradigmático. REVISTA NERA, (46), 08-12.

Palma, C., de Oliveira, A. G., \& Vargas, T. A. V. (2017). As iniciativas de economia solidária presentes em Santa Catarina: análise da microrregião do Alto Vale do Itajaí. Revista NECAT-Revista do Núcleo de Estudos de Economia Catarinense, 6(11), 4359.

Pestoff, V., \& Hulgård, L. (2016). Participatory governance in social enterprise. VOLUNTAS: International Journal of Voluntary and Nonprofit Organizations, 27(4), 1742-1759. 
Pimbert, M. P., \& Moeller, N. I. (2018). Absent Agroecology Aid: On UK Agricultural Development Assistance Since 2010. Sustainability, 10(2), 505.

Prayag, G., Hosany, S., Nunkoo, R., \& Alders, T. (2013). London residents' support for the 2012 Olympic Games: The mediating effect of overall attitude. Tourism Management, 36, 629-640.

Revealing, P. H. (2018). SHORT BREAK. Politics, 1, 48. Sage.

Ridley-Duff, R., \& Bull, M. (2015). Understanding social enterprise: Theory and practice.

Rodrigues, S. J. L., \& Barbosa, J. F. M. (2017). Contabilidade Rural: A Importancia do Contador nas Empresas Rurais de Pequeno Porte no Municipio de Ouro verde de GoiásGO. Anais SNCMA, (8).

Sabourin, E. (2017). Acesso aos mercados para a agricultura familiar: uma leitura pela reciprocidade e a economia solidária. Revista Econômica do Nordeste, 45(5), 21-36.

Salamon, L. M., \& Anheier, H. K. (1992). In search of the non-profit sector II: The problem of classification. Voluntas: International Journal of Voluntary and Nonprofit

Organizations, 3(3), 267-309

Salamon, L. M., \& Sokolowski, S. W. (2016). Beyond nonprofits: Re-conceptualizing the third sector. VOLUNTAS: International Journal of Voluntary and Nonprofit Organizations, 27(4), 1515-1545

Santos, M. (1988). Metamorfoses do espaço habitado. São Paulo: Hucitec,4.Santos, M. (1988).

Schneider, F., \& Zanelli, F. (2017). Texto síntese-Roda de Diálogo SNEA 17. Cadernos de Agroecologia, 12(1).

Silva, S. P. (2014). A trajetória histórica da segurança alimentar e nutricional na agenda política nacional: projetos, descontinuidades e consolidação.

Silva, S. P. (2017). PANORAMA DOS EMPREENDIMENTOS DE ECONOMIA SOLIDÁRIA NO BRASIL: UMA ANÁLISE DE SUAS DIMENSÕES SOCIOESTRUTURAIS. Revista da ABET, 16(1).

Silva, S. P., \& Nagem, F. A. (2016). Dimensões estruturais dos empreendimentos de economia solidária: uma análise para os estados da Bahia e Paraná. Revista Econômica do Nordeste, 43(2), 309-326.

Singer, P., SILVA, R. M. A. D., \& Schiochet, V. (2014). Economia solidária e os desafios da superação da pobreza extrema no plano brasil sem miséria. Brasil sem miséria. Brasília: MDS.

Sonnino, R., \& Hanmer, O. (2016). Beyond food provision: Understanding community growing in the context of food poverty. Geoforum, 74, 213-221.

Spear, R., Cornforth, C., \& Aiken, M. (2009). The governance challenges of social enterprises: evidence from a UK empirical study. Annals of public and cooperative economics, 80(2), 247-273. 
Tenório, F. G. (1999). Um espectro ronda o terceiro setor: o espectro do mercado. Revista de administração pública, 33(5), 85-102.

Tornaghi, C. (2017). Urban Agriculture in the Food-Disabling City:(Re) defining Urban Food Justice, Reimagining a Politics of Empowerment. Antipode, 49(3), 781-801

White, J. T., \& Bunn, C. (2017). Growing in Glasgow: Innovative practices and emerging policy pathways for urban agriculture. Land Use Policy, 68, 334-344.

Yin, Robet K. (2005). Estudo de caso: planejamento e métodos. 2ํㅡ. Ed., Porto Alegre, Bookman.

Yin, Robet K. (2005). Estudo de caso: planejamento e métodos. 2ํㅡ. Ed., Porto Alegre, Bookman.

Zezza, A., \& Tasciotti, L. (2010). Urban agriculture, poverty, and food security: Empirical evidence from a sample of developing countries. Food policy, 35(4), 265-273. 